\title{
Maialen Marin-Lacarta* \\ Mireia Vargas-Urpi* \\ When the Translator Does More than Translate: A Case Study of Translator Roles in a Digital Publishing Initiative
}

\begin{abstract}
Recent technological changes have affected translators' professional boundaries and status. However, scant attention has been paid to the new opportunities that have been created for professional literary translators. Our research focuses on ¡Hjckrrh!, a de facto non-profit self-publishing initiative led by three professional translators who are involved in the publishing of literary translations in ebook format - they share the same professional expertise, but assume different roles in the initiative. An ethnography-inspired qualitative method has been adopted by the researchers. This paper is based on fourteen interviews with participants who have collaborated with iHjckrrh!, comprising eleven translators (including the three founding members of $¡ H j$ ckrrh!), two proofreaders and a graphic designer. The paper aims at studying translators' roles, production teams and relationships, and pays special attention to the agency and visibility of translators. Our findings show that technology has had a positive impact on translator agency, status and identity among the founding members and collaborators of $¡ H j$ ckrrh!. These translators have used the shifting professional boundaries and technological advances to develop their roles as cultural mediators. The article describes the work of the translators who collaborate in this digital initiative and discusses the ways they relate to each other, the roles they play and how they cross professional boundaries. The conclusions identify the relationships and opportunities created by this new work environment.
\end{abstract}

\section{Keywords}

roles; professional boundaries; digital translations; materiality; status; communities of practice.

\section{Introduction}

The impact of digital publishing on literary translations has received scant attention in previous research. In the field of Translation Studies, researchers have focused their attention on related issues such as the influence of digital technologies and the Internet on the work of the translator (Somers 2003, O'Hagan/Ashworth 2002, Austermühl 2001). In the digital humanities, scholars have shown an interest in the monolingual paradigm, which has generated considerable scholarship in recent years, focusing on the creative and interactive potential of electronic texts for literary creation, changes in reading behaviours and the definition of text, among other subjects (Hayles 2008, Pressman 2008).

According to Littau, who undertook a "material history of translation", medial carriers do more than simply conserve or store information, they are constitutive; meaning that literature or culture would be unthinkable without media (Littau 2011: 262). Cronin (2003:9-10) also argued that we should not only pay attention to 'translation and text' or 'translation and translators', we should also examine 'translation and things'. By things he meant "all the tools or elements of the object world which translators use or have been affected by in their work". Buzelin's $(2004,2005$, 2007a) research, based on Latour's Actor Network Theory, shares similar concerns and emphasis-

\footnotetext{
* Maialen Marin-Lacarta Translation Programme Hong Kong Baptist University mmaialen@hkbu.edu.hk
}

\author{
Mireia Vargas-Urpi \\ Department of Translation, Interpreting and East Asia Studies \\ Universitat Autònoma de Barcelona \\ mireia.vargas@uab.cat
}


es the importance of documenting the material transformation of translations and the interactions between the agents involved. In tune with these statements, our research starts from the assumption that materiality impinges on the making of the translation in different ways, and that we need to explore this relationship. We could say that 'translation and things' have an impact on 'translation and text' and 'translation and translators'.

Consistent with the recognition of materiality, some researchers have noted the idea that digital publishing influences translation practice. Coldiron (2012) and Littau $(1997,2011)$ highlighted new possibilities of digital publishing at the textual and paratextual levels. Coldiron (2012: 197) viewed this medium as an opportunity to empower translators and increase visibility: "links to alternative translations, dictionaries, or a translator's site or biography; a video clip of the translator discussing her choices for a particular line" are some of the opportunities that she listed.

Littau (2011: 261) claimed that "if media technologies (from the human body to the computer) make a difference to practices of writing and reading, as historians of the book have demonstrated, then surely the same technologies have also made a difference to practices of translation". Both Coldiron and Littau gave a few examples of the creative use of hypertext and hypermedia links to another node of information and links to information stored in a different media, such as graphics or video, respectively (McKnight et al. 1992: 227) - in translations, but did not address the role of the ebook in shaping new forms of collaboration.

This article uses one particular publishing initiative to examine the changes that ebook publishing has brought to translators' roles, relationships, agency and visibility. We understand agency as "the willingness and ability to act" (Koskinen 2010: 165, italics in the original), which is why the description of the roles taken by translators help us understand their ability to act. In this sense, this paper aims at studying the new roles that have emerged in this environment, the way that the participants' (translators') relationships have been shaped, and the development of translators as cultural mediators, here understood as the initiators or proposers of the translation of literary works as cultural products.

To address these matters, we analyse the content of fourteen interviews with participants who collaborate with ¡Hjckrrh!, a publishing initiative led by three translators that issues literary translations in ebook format. ${ }^{1}$ This article is part of a larger project entitled Digital Translations in the Making: Hong Kong Contemporary Fiction in Spanish ${ }^{2}$, which examines the making of two ebooks ${ }^{3}$ by this publishing initiative.

¡Hjckrrh! was created in 2013 by three Spanish literary translators. At the time of submitting this article, they had worked with twelve translators in the production of nineteen books. Most of the actors involved in $¡ H j c k r r h$ ! are professional translators; there is no formal chief editor, although one of the founding members often assumes this role; and it issues translations of works that are in the public domain or whose rights have been donated by the authors. Translations published by ${ }_{i} H \mathrm{H}$ ckrrh! are designed only to be published as e-books. They are commercialised at a symbolic price through different platforms for all types of e-reading devices, and the earnings are used to cover the costs of their website hosting. We use the term "self-publishing" initiative to refer to them because $i H j c k r r h$ ! is not legally established as a publishing company. Instead, what these translators do is similar to what authors who self-publish their work do: after completing the work, they upload it in Amazon, iTunes and Kobo. The motivations of founding members and collaborators to contribute to this initiative will be explored in a forthcoming article. The very existence of $¡ H j c k r r h$ ! is a demonstration of the importance of the materiality of the ebook, as the translations would not exist without this format.

\footnotetext{
1 More information about ¡Hjckrrh! is available at their website: http://hjckrrh.org

2 Led by Dr. Maialen Marin-Lacarta (Hong Kong Baptist University) and funded by the General Research Fund (GRF 12608815) of the University Grants Committee in Hong Kong.

3 Un paraíso sobre el infierno: tres cuentos de Shanghai, by Liu Na'ou, Mu Shiying and Du Heng; and La cabeza, by Dorothy Tse.
} 
We view translation as a socially situated activity, and this article arises from our interest in learning about the social constraints of translators "as real people" (SelaSheffy/Shlesinger 2011: xii). Other scholars have recently considered the integration of ethnographic approaches as a viable and necessary form of data collection in Translation Studies and a way of enriching sociologies of translation (Wolf 2002; Koskinen 2006; Buzelin 2004, 2005, 2007a, 2007b). This research thus further explores the use of ethnographic approaches in the study of how translators work and learn to work in new (and challenging) environments.

The article starts with two sections that introduce the key concepts and discuss some of the previous research on production teams, translators' roles and professional boundaries. These sections are followed by discussions of our research methodology and the results of our analysis.

\section{Production teams}

Jones (2009: 155) argues that literary translation, as a "form of action in a real world context" (i.e., from a sociological perspective), "may be examined in terms of gradually-widening networks: translation 'production teams'; the 'communities of interest', 'fields' and 'systems' with which teams interact; and the 'imagined communities' in which they operate". For the purpose of our study, the definition of production team is especially relevant. According to Jones (2009: 155), it is an example of a "first order network": a relatively small group of people interacting tightly together for a certain purpose.

Furthermore, production team research assumes that literary translation involves not only translating, but also source text selection, source and target text editing, publishing and marketing. Each team includes various actors and roles: acquisition editor, source writer, translator, chief editor, copy-editor, and proofreader, among others. This implies that the whole team, not just the translator, is responsible for a translation's form, socio-political effects and other aspects of its functioning (Jones 2009: 155).

Research carried out by Buzelin $(2004,2005,2007 a)$ on the print publishing industry in Canada is an excellent example of "production team research", and an important source of methodological inspiration for our own research. Following Latour's (1991) Actor Network Theory, Buzelin studied the making of literary translations from the first negotiation of translation rights to the marketing of the final book. Buzelin (2007a) claimed that we know very little about how translations commissioned by publishers are produced, and there is thus a need for ethnographic descriptions. She documents two interdependent realities: the selection and promotion of foreign texts and the work of translation and editing "from the translator's initial drafts through to the marketed version" (Buzelin 2007a: 140). Therefore, her approach encompasses in a coherent way two realities that are seldom studied together: the transformation of the translated text and the interactions between different actors involved in the making of the translation.

Production team research provides information about how a team achieves the goal of publishing a translation, but also about how translators relate to other actors and the roles they take on. This type of research can be regarded as "agent-grounded research", i.e., research that "analyse(s) translation as a practice from the viewpoint of those who engage in it, in particular (social, cultural or professional) settings" (Buzelin 2011: 6). Literary translators' roles may be shaped by 'norms', which are established within a certain field - a kind of 'second order network' according to Jones (2009) - but their roles may also be related to how they interact with other actors in the "first order network zone" (Milroy 1980: 46, italics in the original) constituted by the production team. The interest in the translator is in fact one of the core reasons for the sociological turn in Translation Studies. In 2009, Dam and Zethsen issued a clear invitation to translation scholars: focus on the translator. According to them, "much more research is needed within this area to gain more knowledge on translators and interpreters as a social and professional group and hopefully in the long run be able to strengthen the status, image and identity of the profession" 
(Dam/Zethsen 2009: 11). Chesterman's (2009: 20) contribution to this issue offered a coherent picture of this new subfield called Translator Studies defined as "research which focuses primarily and explicitly on the agents involved in translation, for instance on their activities or attitudes, their interaction with their social and technical environment, or their history and influence".

In our discussion of the results of our analysis and conclusions, we argue that the idea of a production team as a "community of practice" (Wenger 1999) is valuable. Risku/Dickinson (2009: 51) propose a succinct definition of Wenger's concept and suggest that communities of practice are "informal, self-selecting groups generally formed by volunteer experts who share a common interest in a specific area of competence". In other words, in a community of practice, "the individual members learn by participating in shared activity" (Fox 2000: 853). Researchers in translation and interpreting studies have explicitly used Lave/Wenger's (1991) theory of situated learning and communities of practice. For example, Risku/Dickinson (2009) apply it to the analysis of the virtual community of ProZ.com; Dickinson (2010) observes how sign language interpretation has affected the ways in which deaf and hearing members of a community of practice interact; and D'Hayer (2012) describes virtual learning environments in public service interpreting using the core ideas of communities of practice, among others.

Both Risku/Dickinson's (2009) contribution and D'Hayer's (2012) focus on virtual communities, whereas Dickinson (2010) uses a linguistic ethnographic approach to examine sign language interpretation within the workplace (i.e., face-to-face interactions).

\section{Translators' roles and boundaries}

The outcomes presented in this paper are part of a research project that has documented the making of two translations in order to explore whether the materiality of the e-book empowers translators, to shed light on the relationship between power, motivation and collaboration, and to illustrate the workflows and roles emerging in the context of an 'informal' publishing initiative. In this paper, we aim to describe translators' roles in the context of this case study.

Most previous studies of roles within Translation Studies have actually been produced in the context of interpreting. For instance, a search for role in the subject index of the Handbook of Translation Studies edited by Gambier/van Doorslaer (2010-2017) refers only to interpreting (see Figure 1).

\section{Role (of interpreter) see Community interpreting; Conference interpreting; Court/Legal \\ interpreting; Interpreting Studies; Interpretive approach; Simultaneous \\ interpreting}

Figure 1. Screenshot from the "Subject index" of the Handbook of Translation Studies.

Indeed, the literature on interpreting and especially on community interpreting (and court interpreting) has paid enormous attention to the role of the interpreter in mediated interactions. This research has tried to shed light on the much debated dichotomy of the interpreter as a conduit (or as a 'translation machine') versus the interpreter as a coordinator of the conversation or even an intercultural mediator who actively participates in the exchange to enhance mutual understanding (some of the most representative include Angelelli 2004; Hale 2007, 2008; and Wadensjö 1998). In Translation Studies, a similar debate has also taken place under the umbrella of the translator's (in)visibility (Venuti 1995). Invisibility may be related to the translator's position as a co-producer of a text, to the invisibility of the translator's activity within the text of the translation itself or to the invisibility of translation as a cultural practice and as a cultural product (Emmerich 2013). 
Koskinen (2000) suggested a similar three-level distinction, namely, paratextual, textual and extratextual (in)visibility. Venuti's work, however, is mostly textual: he describes the invisibility of the translator's activity mainly within the text of the translation itself. We could say that he pays attention to 'translation and text', but not to 'translation and translators'.

A similar debate has been presented by Katan, who has advocated for translators to become intercultural mediators (Katan 1999) or even transcreators (Katan 2016) - that is, translators who do not strictly adhere to a faithful rendition of the original, but instead manipulate it to provoke in the target reader the same effect that original readers would have. 'Transcreators' may manipulate the original to a higher degree than intercultural mediators. For Katan, these possibilities empower translators and make them more competitive - especially compared with automatic translation software - while also recognising their creative role and "authoriz[ing] them to take account of the impact of cultural distance when translating" (Katan 2016: 378).

The concept of 'intercultural mediator' mentioned above is different from the notion of 'cultural mediator'. Cultural mediation is here understood as the act of endorsing or proposing the translation of literary works as cultural products. In a similar vein, the notion of 'translation initiator' has been defined by Hewson/Martin (1991: 113) as the "driving force behind the act of Translation, and whose identity and express wishes have a fundamental influence on the Translation operation." Nord (2005: 9) explains that "the initiator is the factor that starts the process and determines its cause by defining the purpose for which the translated text is needed".

Peña (1997) prefers the use of "protranslator" for its wider scope, as it covers both the ideainitiator, the process-initiator and even the commissioner. This concept is applied by Lin (2012), who examines seven translations of Platero y yo from Spanish into Chinese and concludes that, in her sample, when the translator is also the protranslator, a more foreignising method is used. In contrast, when the protranslator is a publishing company, a more domesticating method is applied.

Finally, it may be interesting to relate the study of the translator's role to the study of boundary work in the translation profession. Grbić (2010) borrowed the notion of "boundary work" from Gieryn (1983) and introduced it to Translation Studies as a fruitful concept to study professionalization processes. According to Koskinen/Dam (2016: 254), paraphrasing Gieryn (1983): "Boundary work typically refers to practitioners' own negotiations between those claimed to inhabit the inside and those assumed to remain outside". Grbić applied it to the case of sign language interpreters in Austria and was interested in the following research question: "What happens in the process of constructing sign language interpreting as a profession in Austria?" (2010: 118). Koskinen/Dam, on the other hand, explored how boundaries are constructed and assumed by researchers in a series of articles published in a special issue on the translating profession. These publications suggest that research on boundaries has focused on 'who' belongs to the profession: insiders vs. outsiders or professional vs. a non-professional translators and 'how' these boundaries are constructed (the process). We propose that boundaries can also be studied from the perspective of 'what': what belongs to the profession, what roles and tasks 'insiders' take on, what they regard as outsider's tasks and what kinds of tasks they engage in when they consciously cross boundaries. This study suggests that crossing those boundaries may be common in some contexts.

\section{Methods}

Given the objectives of the study, i.e., to describe the work of translators, the roles they assume and the new relationships that arise in a digital publishing initiative, an ethnography-inspired qualitative method was chosen. The principal investigator (PI), Maialen Marin-Lacarta, has been involved with ${ }_{i} H \mathrm{jck}$ rrh! since 2014 and her translation of three stories from Shanghai (Un parai-

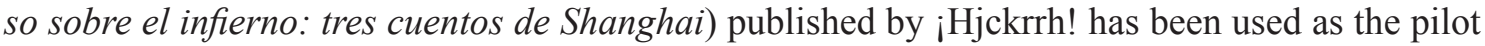
study for this project. Due to the involvement of the PI, new participants have joined this initiative and further publications of literary translations are in progress. Our method is ethnography- 
inspired as it involves participant observation, fieldnotes in the form of collaborative diaries, and interviews. This has allowed us to study the process of translation and publication in the making. In this sense, ethnography differs from other methods, such as "history and archaeology in that it is based on the direct observation of living people rather than on written records or material remains attesting to the activities of people in the past" (Ingold 2008: 70). The PI in this case has a tripartite identity, as a researcher, a participant and an observer. In her role as participant, she has also been interviewed by the co-investigator in an attempt to include her views as translator in this study.

The data collection for the overall project included data from multiple sources: (a) self-reports from the participants gathered from (i) fourteen in-depth interviews, including one with the PI, and (ii) reflective diaries written by the agents involved in the making of one of the works pub-

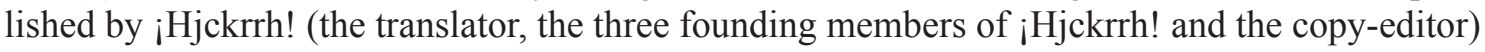
and the two researchers; (b) internal documentation of the publishing initiative, such as emails exchanged among the participants to document the interaction between the different agents; and (c) drafts and paratexts of the works published by ${ }_{i} H j \mathrm{jckrrh}$ ! including the cover, preface, postface, footnotes, webpage, blog entries and tweets.

In this article, we present the findings from the interviews conducted with the three founding members of $¡ H j c k r r h !$, eight translators (including the PI) that have translated literary works published by ${ }_{i} H j \mathrm{ckrrh}$ ! before September 2016, the cover designer and two proofreaders. We also use information from the email correspondence and our fieldnotes to complement the data (the workflow described in section 5.3. is based on these sources). The interviews were informal and semistructured. There was a list of questions and topics to be covered during the interviews, but it was not a fixed guide, and questions were adapted to the interviewees' answers. New questions were added and the order of questions was changed when, as interviewers, we felt these changes could help us obtain additional or relevant information. Participants were asked to talk about their professional background, the origin of their involvement with ${ }_{i} H j \mathrm{ckrrh}$ !, each step of the process (the translation, the submission, the revision, the choice of the cover, the preface, the synopsis, the information on the website...), their interactions with other participants, and how they would compare this experience with other professional experiences.

All informants signed an informed consent ${ }^{4}$. Eight of the interviews were conducted in person and four by videoconference (Skype), and one of the informants (a translator) requested to provide written answers to the questions. With this exception, all of the other interviews were voicerecorded. It must also be noted that the interviews with the founding members of the digital publishing initiative - which were substantially longer due to their wider implication - were jointly conducted by the project's two researchers. The other interviews were conducted by only one of the researchers.

The interviews were conducted in Spanish and transcribed verbatim. These transcriptions were then coded by means of Atlas.ti, a software program for qualitative data analysis. Atlas.ti's interface displays the transcription, and excerpts can be selected and assigned codes (see Figure 2 for an example). Excerpts can then be retrieved and classified according to these codes. For the sake of this article, the excerpts used have been translated into English by the researchers.

4 This project was submitted to and approved by the Board of Ethics of Hong Kong Baptist University. 


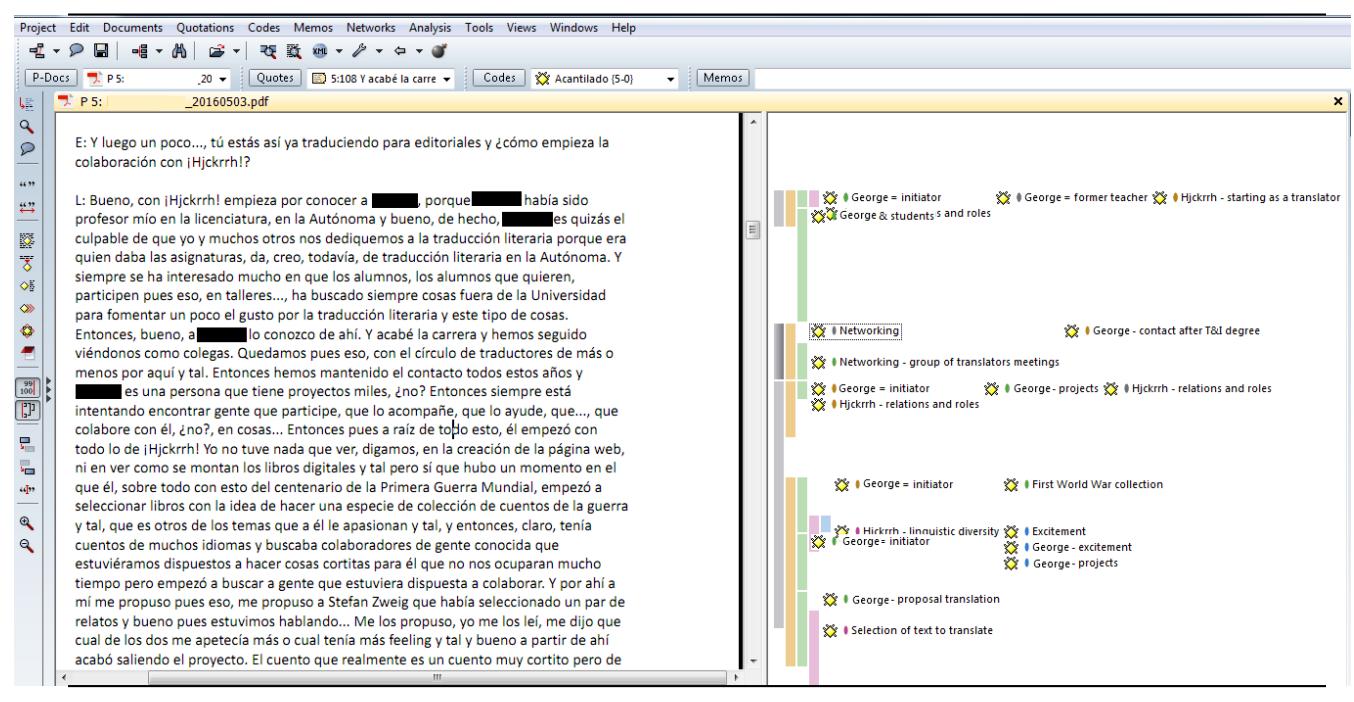

Figure 2. Screenshot of Atlas.ti's coding interface

Qualitative content analysis (Mayring 2000) was used to assign codes and develop a formative analysis (inductive and deductive), as some codes were related to our research questions or objectives and foreseen in the interview guides, but some unexpected codes were deemed important to include in our analysis.

The qualitative content analysis using Atlas.ti was divided into the following stages.

1. Each researcher analysed the same three interviews (two interviews with the founding members and one interview with a translator). Codes emerged from the analysis conducted in Atlas.ti, based on the project's objectives and research questions.

2. After analysing these three interviews, each researcher's codes were compared and commented, producing a unified list of codes and criteria.

3. Each researcher analysed again the interviews that the other researcher had conducted in the first step, according to the unified list of codes and criteria. We provided feedback on the analysis to each other.

4. Each researcher then analysed half of the remaining interviews following the unified list of codes and criteria.

5. Each researcher reviewed the other researcher's analysis.

Our coding system was highly specific. For instance, the code 'Gerardo = initiator' was only used when Gerardo ${ }^{5}$, one of the founding members of ¡Hjckrrh!, was mentioned as the initiator of a given translation. We could have chosen a more general code (e.g., 'initiator') that was applicable to all of the actors who took on that role. However, having more specific codes illustrated the prominence of some actors. As a matter of fact, 'Gerardo' appears in 20 codes, which reflects his central position in the production team. Although participants do not use any specific term to refer to his role, he acts as the chief editor. Each excerpt was assigned more than one code if it was related to various ideas, as may be seen in Figure 2.

5 The participants' names have been anonymised; we use pseudonyms instead. 
The analysis resulted in 239 codes. For the purpose of our research, codes were grouped into fourteen 'families' or general topics. Figure 3 shows the interface of the Code Manager, where each code is classified into a family.

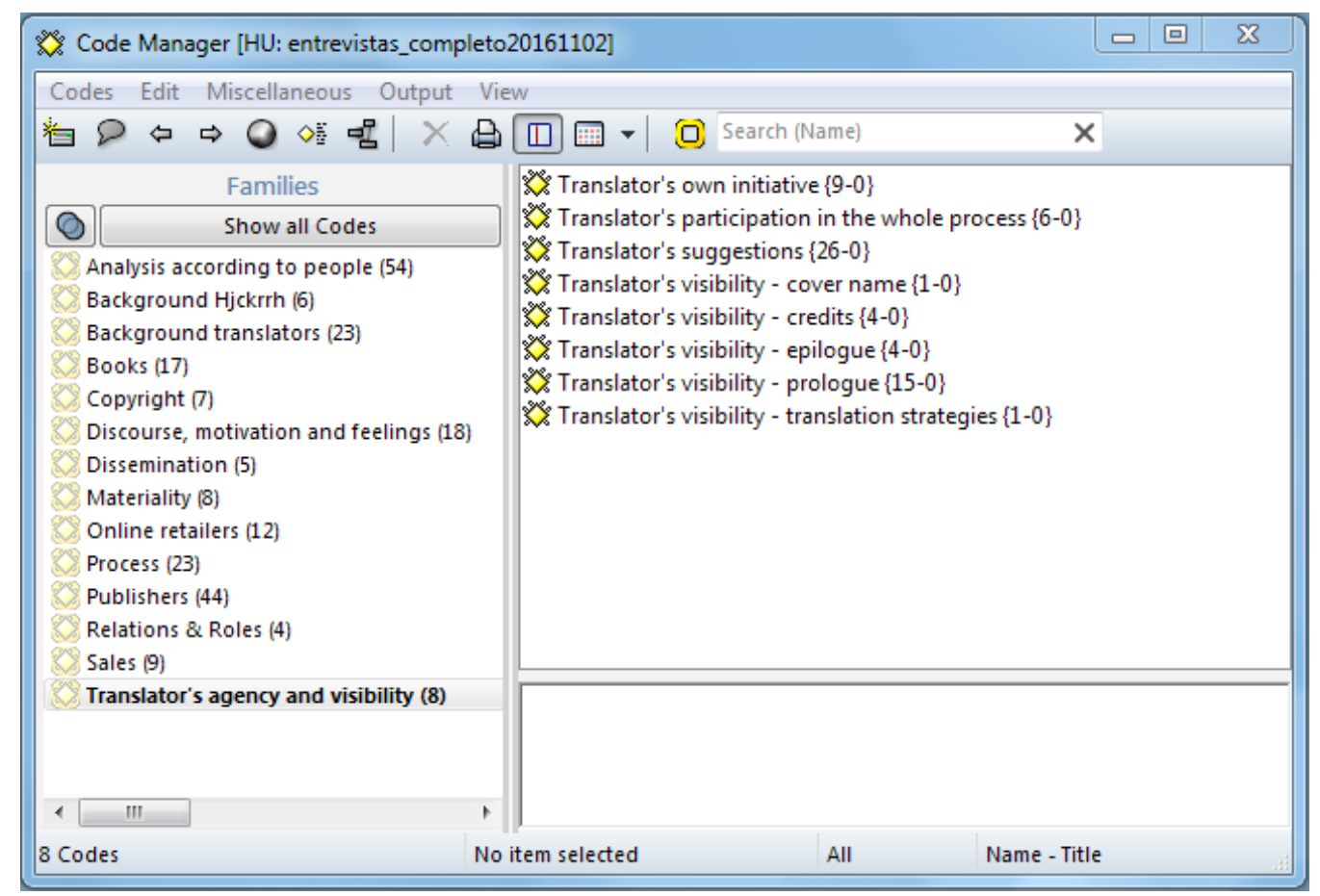

Figure 3. Screenshot of Atlas.ti's code manager's interface

Out of those fourteen families, five are related to the issues examined in this article.

\section{Results}

This section is based on the analysis of the codes included in the five families of codes presented in Table 1 . The table also gives a brief description of each family and the rationale for their relevance to this article. 


\begin{tabular}{|l|l|l|}
\hline Name of the family & Description & Relevance \\
\hline Actors & $\begin{array}{l}\text { Excerpts that explicitly } \\
\text { mention people involved } \\
\text { in the initiative and their } \\
\text { contribution. }\end{array}$ & $\begin{array}{l}\text { Specific references to people } \\
\text { often involve talking about } \\
\text { the role they take on. }\end{array}$ \\
\hline Background of ¡Hjckrrh! & $\begin{array}{l}\text { Excerpts related to the origins } \\
\text { and establishment of the } \\
\text { digital publishing initiative. }\end{array}$ & $\begin{array}{l}\text { Both the division of roles } \\
\text { and the importance of the } \\
\text { materiality of the ebook are } \\
\text { sometimes mentioned. }\end{array}$ \\
\hline Dissemination & $\begin{array}{l}\text { Excerpts where participants } \\
\text { explain actions undertaken to } \\
\text { promote e-books published } \\
\text { by ¡Hjckrrh!. }\end{array}$ & $\begin{array}{l}\text { Disseminating translations is } \\
\text { one of the possible tasks that } \\
\text { translators fulfil. }\end{array}$ \\
\hline Relations and roles & $\begin{array}{l}\text { Excerpts where actors explain } \\
\text { how they relate to each other } \\
\text { and the roles they take on. }\end{array}$ & $\begin{array}{l}\text { Description of roles and } \\
\text { relations are an essential } \\
\text { question addressed in this } \\
\text { article. }\end{array}$ \\
\hline Translators' agency and \\
visibility & $\begin{array}{l}\text { Excerpts that reflect } \\
\text { translators' agency and } \\
\text { visibility in this work and } \\
\text { ablishing environment, such } \\
\text { in the publishing process } \\
\text { including translation } \\
\text { proposals, cover proposals, } \\
\text { translator prefaces, translator } \\
\text { epilogues, etc. }\end{array}$ & $\begin{array}{l}\text { The relationship between } \\
\text { materiality, agency and } \\
\text { visibility is interrogated. }\end{array}$ \\
\hline
\end{tabular}

Table 1. Families of codes used in this analysis

\subsection{Description of the sample of informants: Relations and networks}

The sample of fourteen informants is composed of actors who have participated to a greater or lesser extent in ¡Hjckrrh!, the publishing initiative under study. Among the fourteen informants, twelve are translators with previous experience in literary translation. The twelve translators have the following characteristics.

Three founding members of $¡ H j c k r r h$ ! 
- Gerardo: professional literary translator with more than thirty years' experience, lecturer of Translation at university.

- Juan: professional literary translator with twenty years' experience, friend of Gerardo. He has some experience as book editor in a publishing house.

- $\quad$ Roger: professional literary translator and former student of Gerardo twenty years ago.

\section{Collaborators}

- Daniel: professional literary translator, former student of Gerardo fifteen years ago, and lecturer of Translation at the same university as him.

- Lara: professional literary translator, and former student of Gerardo twenty years ago. She has worked with Roger in previous collaborative translation projects.

- Lidia: studied translation but now works in a different unrelated field. Former student of Gerardo twenty years ago.

- Amaia: professional literary translator, lecturer of Translation at a different university and former student of Gerardo thirteen years ago.

- Cecilia: professional literary translator with more than thirty years' experience, and friend of Gerardo.

- Felipe: professional literary translator with forty years' experience, lecturer of Translation at a different university, and friend of Gerardo.

- Raul: professional literary translator with twenty years' experience, lecturer of Translation at a different university, has been in touch with Gerardo for teaching and research purposes.

- Julia: a former music teacher from Hungary who started translating after retiring. She attended a translation summer school given by Abel, a well-known HungarianSpanish translator. Abel put Julia in touch with Gerardo. She translates together with her husband, Ángel, a native Spanish speaker.

- Simona: professional translator with little experience in literary translation. Her collaboration with $¡$ Hjckrrh! has been limited to revising one translation (checking it against the source text). Amaia put her in touch with Gerardo.

- Mario: an artist and professional designer. He designs the front covers and is also Gerardo's friend.

- Sofía: a psychologist, has participated as a proofreader of the final version of the texts (her name also appears in the e-books' credits). She is Gerardo's wife. 


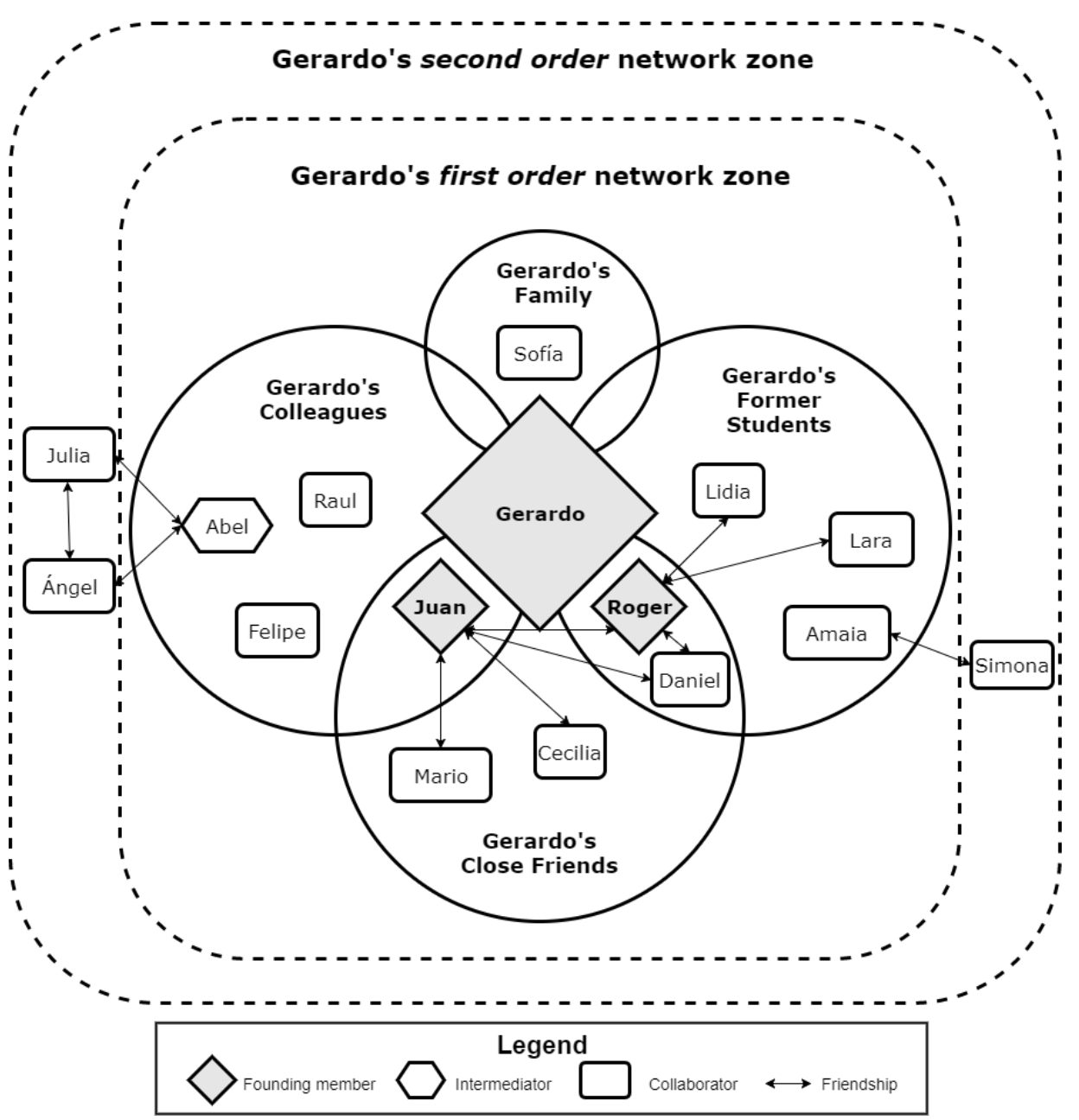

Figure 4. Map of relationships between actors

Figure 4 presents a map of the relationships of the actors who have participated in $¡ H j c k r r h !$. As can be seen in Figure 4, Gerardo is a pivotal person in the development of the production team: with the exception of Julia, Ángel and Simona, all of the other actors started collaborating with $¡$ ¡Hjckrrh! because of their direct contact with Gerardo, either as former students or as friends and relatives. Figure 4 also shows how some of the participants know each other. Some are close friends, whereas others have more collegial relationships. We have tried to reflect the complexity of the network in this figure, although it is difficult to categorise relationships.

\subsection{Roles, agency and visibility: Translators as prefacers, copyeditors, proofreaders, editors, testers...}

As already mentioned in the previous section, with the exceptions of Mario (front cover designer) and Sofía (proofreader), all of the participants are professional translators or have previous experience in the field of literary translation. However, as $¡ H j$ jkrrh! functions as a digital publishing initiative, the translators have also taken on roles that are traditionally attributed to publishing editors, copy-editors, designers, marketing managers, etc.

Roles in our corpus are classified according to two different distinctions. First, with regards to the 'materiality' of the e-book, we distinguish between (a) traditional roles, or the roles that would also be found in print publishing houses, and (b) 'digital' roles, or the roles that are more tightly 
related to the digital creation and distribution of the e-book. Second, with regards to the boundaries of the translator's work, we distinguish between (i) translation-related roles, or roles that are often placed inside the boundaries of translation, such as revising others' work or writing a preface or an epilogue; and (ii) self-publishing-related roles, or roles that go beyond the boundaries of translation and are more related to the activity of self-publishing, such as finding collaborators or negotiating translation rights.

In this article, we principally focus on the ways participants relate to each other, the roles they play and how they cross professional boundaries. For this reason, the second distinction (translation-related roles vs. self-publishing-related roles) is used in our analysis and conclusions.

\title{
5.2.1. Increased agency: Translation-related roles
}

With the exceptions of Sofía, Mario and Simona, all of the actors have collaborated with ¡Hjckrrh! as translators, and most have also taken on other roles. The only translator who has translated only is Lidia, translator of Lady Nicotina (My Lady Nicotine). In fact, her case is rather an exception, as she had already translated and published this book some years before with a publishing house that later disappeared. She had the digital rights to the translation and Roger encouraged her to publish

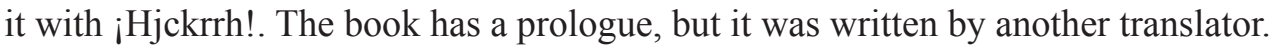

Seven of the eleven translators interviewed have written a prologue or epilogue for their translation. According to the interviews, it is usually Gerardo who encourages translators to write prologues. Cecilia, who has refused to engage in this task, explains that "Gerardo (...) loves prologues. He is always telling us, 'You have to write a prologue', but I said, 'No, no, no, not me (...) I'm very perfectionist and it would take me too long"'.

Lara also explains how the idea of the epilogue included at the end of Incidente en el lago Leman (Episode am Genfer See) emerged.

\section{Extract 1. Lara, translator}

\begin{abstract}
Then Gerardo told me, 'Look, it would be nice to keep all this information and then use it to write something, it's up to you: maybe you can compile all the interesting information that you have found, or an introduction to prepare the reader for the story, or a commentary about the translation... It's up to you, but don't let all that information get lost. All this process that in the end is what excites you about the translation, all the things you find behind the story and that you normally keep to yourself as a translator... don't let them get lost, share them somehow'. And well, I think that, in general, all the projects in ¡Hjckrrh! are short stories, but carefully chosen and very special, I think that he always tries to include a prologue, epilogue or commentary, sometimes written by the same translator, sometimes written by colleagues. And in this case there were many things to comment on, but it had to be an epilogue, I preferred to write an epilogue (...) not to offer a spoiler of the story.
\end{abstract}

There are two key ideas in the previous excerpt that are worth mentioning. First, the prologues, epilogues and commentaries are points of visibility (Coldiron 2012) or paratextual visibility (Koskinen 2000) for the translator - traces of the translator's presence. Furthermore, Lara's words seem to indicate that there is a clear intention of making translators' work visible in these paratexts. Gerardo's emphasis on the importance of sharing the results of translators' documentation tasks may even be a form of advocacy for the visibility of the translator. ${ }^{6}$ Second, this excerpt illustrates the desire to empower the translator, who has the final decision about what to include in these paratexts (in Lara's case, an epilogue), but also the freedom to refuse to write one, as in Cecilia's case. Translators are empowered, and this may increase their agency, understood as their ability to act (Koskinen 2010), as well as their paratextual visibility (Koskinen 2000). However, agency also means that translator may choose "not to act" and thus remain less visible.

6 Another evident point of paratextual visibility is the inclusion of the names of the translators on the front covers of the e-books. 
In the preceding excerpt, Lara also mentions that the e-books published by ${ }_{i} H j \mathrm{jckrrh}$ ! are "short stories, but carefully chosen and very special". Lara uses an impersonal form ("carefully chosen"), but the analysis of the body of interviews indicates that Gerardo plays a key role in the selection of texts to translate and in launching the translation process. As already mentioned in Section 2, the translator is sometimes the translation initiator (or protranslator), but in the context of $¡ H j c k r r h !$ it is Gerardo in his role of translator-editor who usually selects a text, or in some cases, various texts, and encourages his colleagues to translate it. For example, in Lara's case, Gerardo proposed various short stories and she chose to translate one of them. Gerardo acknowledges this role: "up to now, I've selected the texts"; "Yes, I've chosen all the stories. The World War I collection is composed of texts I selected. I'm open to suggestions, but up to now I have done all the selections". There are three exceptions to this until now:

1. Juan's translation of a Catalan story into Esperanto.

2. Daniel's retranslation of an Italian story related to World War I. Daniel explains that the existing translation was "not very good" and that he wanted to "experiment" with this text and produce a new translation.

3. Amaia's translations of three Chinese stories into Spanish.

Nevertheless, although Juan, Daniel and Amaia chose the texts they translated, it was Gerardo who encouraged them to suggest a translation to publish digitally in iHjckrrh!; thus, he maintains the role of the 'idea-initiator'.

Three of the translators interviewed have also engaged in revising or proofreading translations: two of the founding members (Gerardo and Juan) and Cecilia. In his role of translator-editor, Gerardo has revised and copy-edited all of the e-books, with the exception of Juan's translation into Esperanto, which was revised by external collaborators. Cecilia has also done copy-editing, especially of Gerardo's translations. Juan's revision is a proofreading, which he carries out while and after converting the text into an ebook, with some aspects of copy-editing, as he may also correct typos, and propose stylistic changes. Another regular proof-reader is Sofia, who gives her opinion as an 'outsider', i.e., as a reader without specific training or experience in translation.

\subsubsection{Crossing boundaries: Self-publishing roles}

Although most of the participants in $¡ H j c k r r h !$ are translators, and this may suggest that they all share the same status and hierarchy, there are clear differences between the roles taken on by the founding members (whose commitment to the project is stronger) and those taken on by the translators who only participate in the translation of a specific text and its prologue or epilogue. Thus, the roles that are more related to ${ }_{i H j} \mathrm{Hckrrh}$ ! as a digital self-publishing initiative are mainly assumed by the core team of the founding members. These tasks, which are often outside the translator's training and expertise (and thus, cross professional boundaries), are briefly described as follows.

(a) Recruitment of translators and collaborators

Although the common practice in Spain is the advance against royalties, translators who have collaborated with $¡ H j$ jkrrh! do not expect any economic reward for their translations. They are entitled, a posteriori, to a percentage of the e-book sales; however, as of the date of drafting this article, no payment has been made yet. Most of the e-books are short stories that are sold for less

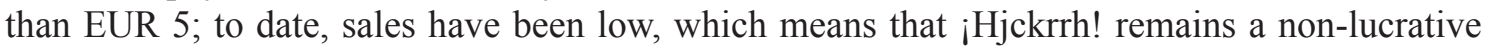
publishing initiative. This information is important to contextualising the task of finding new translators to participate in the initiative.

Gerardo has encouraged most of the translators and the graphic designer to collaborate with ¡Hjckrrh!. Our informants give various reasons for accepting this proposal, but the common denominator is friendship. In the following extracts, Gerardo describes this task. 
Extract 2. Gerardo, translator and founding member

All of the collaborators are people that I know from the faculty or... most of them... There you find people with similar interests and I suggest to them that they participate because I think they'll be able to participate. To date, nobody has refused to participate, well, only Abel because he did not have time (...) But in the end he has also helped us find other translators.

Extract 3. Gerardo, translator and founding member

I talk to people and I tell them, 'Look, this is an experiment, an investment-experiment', I tell them a little bit about the project (...) they are all translators whom I trust, they know us and they are excited to experiment with this. And they have agreed to participate, they agree to translate a story. Normally I suggest the story, but I'm open to proposals.

The desire to publish a multilingual anthology of World War I forced Gerardo to search beyond the circle of former students and friends and relatives and to find translators from languages such as Hungarian (Julia) or Turkish (Raul), as can be seen in Figure 4.

On four specific occasions, ${ }_{i} H \mathrm{H}$ ckrrh! has published already-existing translations that were originally intended for print. One of these examples was Gerardo's anthology of translations of stories of the Great War, Cuentos de la Gran Guerra. This book had been published by another publishing house in 2008, and Gerardo had tried to convince the publishers to prepare a special edition of the book to commemorate WWI in 2014, or at least to relaunch it on that occasion. According to his own words, the editors "had not paid much attention", and as he had retained the digital rights to the translation, he decided to self-publish it with ¡Hjckrrh!.

Gerardo's translation of Alicia en el país de las maravillas (Alice's Adventures in Wonderland) by Lewis Carroll was a similar case. Gerardo had recovered the translation rights and Roger suggested publishing it as an e-book with ¡Hjckrrh!.

Extract 4. Roger, translator and founding member

\begin{abstract}
And, it just happened that some years ago Gerardo had translated Alice in Wonderland for [name of a publishing house], and I knew that he had recovered the translation rights and I said, 'Well, why not? I mean, it costs nothing. Take it, upload it and then it's you who sells it. And instead of the $2-3 \%$ that [name of a publishing house] gives you, Amazon will give you a 70\% and you'll be rich'. I didn't say it like this because I knew the book would not sell that much, but, well, now it's there.
\end{abstract}

The other two examples follow a similar rationale: Felipe already had a translation of El guardavia (The Signal-Man) by Charles Dickens, which was intended for a print publication. In fact, some time ago, Gerardo had convinced Felipe to publish this short story with a traditional publishing house. Felipe had submitted the translation and been paid for it, but in the end the translation was never published. Gerardo then realised that the translation could be published as an ebook by ${ }_{i} H \mathrm{H}$ ckrrh! and suggested this idea to Felipe, who accepted.

Finally, the last example has already been mentioned: Lidia's translation of Lady Nicotina by J. M. Barrie. In this particular case, the idea to publish this book digitally also came from Roger.

(b) Negotiation of translation rights

¡Hjckrrh! sells e-books in commercial platforms, but none of the participants in the interviews mention the idea of making a profit as a reason for working with ¡Hjckrrh!. ¡Hjckrrh! only publishes translations of books that are already in the public domain or with copyright that has been transferred for free by the authors or right-holders.

In most cases, if works are already in the public domain, there is no need to negotiate rights. However, as copyright term lengths vary across countries, and some of the books $¡ H j$ ckrrh! publishes have previously been published by other publishing houses, some negotiation is necessary before uploading certain e-books to online retailer platforms. The following examples are mentioned in the interviews. 
1. Pirandello's Berecche y la guerra (Berecche e la guerra). At the time they tried to upload this book to Amazon, it was in the public domain in Italy, but not yet in Spain. Gerardo asked a colleague for help and they both wrote letters to Pirandello's House and Museum in Sicily and to the association of Italian writers, who suggested asking another person. In the end, they did not get replies and the book could be uploaded only to Amazon's UK platform (not to the Spanish platform).

2. Karinthy's Viaje a Faremido (Utazás Faremidóba). There was a similar problem for this book and, according to Juan, the copyright length was unclear. The translator of the book, Julia, contacted the authors' heirs and they transferred the rights for free.

3. Dickens' El guardavia. There is already a translation with the same title in Spanish published by another publishing house, and the online retailers feared that this was a pirate copy that had been illegally uploaded. Gerardo and Roger had to prove that this was a different translation of the same book. In the interviews, Gerardo and Roger mention similar problems with other books.

4. Solana's La unua seria murdisto de la (pra)historio (El primer assassí en sèrie de la (pre)historia). The translation rights were transferred by the author, a friend of Juan (the translator) and Gerardo.

Karinthy's translation rights were a special case: because of the language barriers, they had to rely on the translator to contact the author's heirs. In the other cases where copyright problems have prevented them from uploading certain books, Gerardo and Roger (who is in charge of uploading the books to the online retailer platforms) have prepared the required documentation and sent it to the online retailers.

(c) Formatting the e-book

Juan is in charge of 'making' the e-book, i.e., transforming the text into mobi and epub versions. When talking about the origins of ¡Hjckrrh!, Juan explains that he "committed to all the tasks related to IT, the web or the making of the ebook". Juan admits that he spent a long time formatting the first e-books, as he was actually learning how to make them at the same time. He explains that he found it very difficult at the beginning, as the programming language was not very user-friendly. Furthermore, certain books have specific difficulties, such as Alicia en el país de las maravillas, which has illustrations that have to be adapted to each different e-reader device. Throughout the interview, Juan emphasises the self-learning process.

(d) Design of the book cover

The first three e-book covers were designed by Juan after discussing some ideas with Gerardo. Juan explains that he taught himself how to do this, but as Gerardo "wanted a (high) level of perfectionism, it was good that Mario took this over". Mario is a professional graphic designer who has designed the rest of the e-book covers, usually based on Gerardo's suggestions of photographs or images. The only two translators who mention having suggested possible images for the cover are Amaia, who sent some pictures of Shanghai in the 1930s to Gerardo, and Raul, who sent a photograph of a painting to Gerardo. In both cases the images suggested by the translators were used in the e-book cover. These are also examples of translators' agency in the context of $¡ H j c k r r h$ !: translators know their ideas will be listened to and thus are eager to participate in other stages of the making of the e-book.

On one occasion, a public survey was organised to vote between two potential book covers. The survey was available online through the blog ${ }^{7}$ and was forwarded mostly to ¡Hjckrrh!'s collaborators.

(e) Testing the e-book

7 http://bloc.hjckrrh.org/duda/ 
Once the e-book formats are ready, they are tested in different e-readers, just to make sure that the final layout is the same regardless of the device. Juan, Gerardo and Cecilia participate in this task.

(f) Uploading the e-book to online retail platforms and managing sales

Roger is in charge of uploading the e-books to Amazon and iTunes. Gerardo is in charge of uploading the e-books to Kobo, the third platform used by ¡Hjckrrh!. To make the e-books available on these platforms, Roger and Gerardo have to fill in user registration forms, provide the required information to upload the e-books, interact with retailers whenever any technical or legal problems arise (as in the case of translation rights) and manage sales (access sales records and monitor reimbursement of sales).

Kobo is perhaps the more user-friendly platform, whereas using Amazon is a bit more cumbersome, according to Roger and Gerardo. However, more e-books are sold through Amazon than through Kobo.

(g) Dissemination of the e-books

Gerardo is in charge of the dissemination of the e-books, a task that could be considered equivalent to the 'marketing' task in a traditional publishing house. He asks translators to provide a short biography of the original author for the ${ }_{i} \mathrm{Hjckrrh}$ ! webpage. (If the translator is not available, he writes it himself.) He also prepares a brief summary of the book and five external links that are in some way related to the story (such as videos, songs, maps or documents relating to the story). Juan then posts all of this information to ¡Hjckrrh!'s webpage.

Gerardo updates the blog, where he posts information related to the e-books published by ¡Hjckrrh!. He also manages ¡Hjckrrh!'s Twitter and Facebook accounts, where he announces new publications. Gerardo explains that Roger was originally in charge of social media, but became too busy with other things later on, and Gerardo had to take on these added tasks. Half-laughing, Gerardo complains that they "need a community manager".

Daniel, Lara, Cecilia and Amaia also announce the publication of their translations and other e-books published by $i$ Hjckrrh! on their own social media accounts.

\subsection{Roles, tasks and workflow}

In brief, the previous tasks can be summarised in the following workflow, which seems to be recurring in ¡Hjckrrh!:

1. Commission or proposal of a translation. Gerardo is often the initiator who selects the text and engages a translator. Although in three out of twenty cases the translators themselves were the initiators who selected the text, it was still Gerardo who encouraged them to propose a translation and publish it digitally in ¡Hjckrrh!; thus, he maintains the role of the 'idea-initiator'.

2. Acquisition of translation rights. One of the selection criteria for most translations has been the fact that their copyright had expired; in most cases both Gerardo and the relevant translator have verified the status of the copyright. In cases where the translation rights were retained by the authors or their descendants, the translator has approached them in order to obtain such rights. In all instances, the owners of the translation rights have agreed to transfer them at no cost.

3. Translation. Translators translate the text, at their own pace and with total flexibility and without any imposed deadline. They might also write a preface or postface. As part of the translation itself, translators check their draft against the source text.

4. Revision and editing. The translation draft is then sent to a second translator who is proficient in the same language combination. This second translator revises by 
comparing the translation against the source text to ensure accuracy and completeness of translation.

4.1. The revised draft is returned to the first translator, who may accept or reject any changes or suggestions made by the reviser. This usually is a back-and-forth process, with several exchanges between translator and reviser.

4.2. Editing. The resulting draft is then passed on to a copy-editor, usually Gerardo, who then reads the translation and performs stylistic editing and proofreading.

4.3. The resulting draft is returned to the first translator, who may accept or reject any changes or suggestions made by the editor. This usually is a back-and-forth process, with several exchanges between translator and copy-editor.

5. Cover design. Depending on the motivation and implication of the translator, he or she may propose a particular design for the cover. Otherwise, Gerardo would make suggestions. Once a consensus is reached, Gerardo sends the images and cover information to Mario, the graphic designer.

6. E-book 'making'. The final translation draft and the designed cover are then sent by Gerardo to the e-book maker, Juan, who converts the translation draft, from a text document into an e-book in mobi and epub formats.

6.1. Being a professional translator and copy-editor himself, Juan may also correct any typos he might find while formatting the e-book or suggest further stylistic changes.

7. Proofreading. Once the translation is in e-book format, Gerardo, the original translator and other proofreaders, such as Sofía or Cecilia, re-read the translation in different devices to ensure that it is displayed correctly across different platforms.

7.1. If any of the proofreaders detects a typo or suggests new stylistic changes, Juan issues a new version of the e-book and the proofreading process is re-started.

8. Publication. Gerardo uploads the final e-book to Kobo and sends it to Roger, who uploads it to Amazon and iTunes.

9. Dissemination. Juan is the administrator of ¡Hjckrrh!'s website and Gerardo and Roger manage ¡Hjckrrh!'s social accounts.

9.1. Gerardo and the translator collect and draft the relevant information about the book and the author for the website. This includes but is not limited to author's biography, summary of the translation, and screenshots of the e-book.

9.2. Gerardo sends this information to Juan, who posts it the webpage dedicated to each translation.

9.3. Gerardo posts about the new publication on social media (blog, Facebook and Twitter).

9.4. The translator and other collaborators might also share the new publication on their social media. 


\section{Discussion: Roles, pushing boundaries and ¡Hjckrrh! as a community of practice}

Most of the participants in ¡Hjckrrh! are translators with similar professional background, but there are clear differences between the roles of the founding members and the collaborators. This is understandable: the founding members' commitment is stronger. Nevertheless, translators' suggestions are taken into consideration and, when available, translators have been relied on to participate in other tasks. Cecilia is a good example of this: in addition to her own translation, she has revised translations and tested formats in her e-reader. The making and publishing of translations is undertaken by a team of translators who can therefore be regarded as cultural mediators.

Due to these different levels of commitment to and involvement in ¡Hjckrrh!, it is difficult to talk about horizontal relations between the participants in the production team. Gerardo is certainly a key actor, a leader who is not only a link between all of the other participants, but also responsible for keeping the project active and alive by finding new translators, suggesting books to translate and extensively revising them to ensure the quality of the final product. Juan and Roger's roles in the self-publishing process are more technical and specialised.

In the 'core team' of founding members, roles are relatively defined (each of them knows his position in the production team), but flexible. For example, Gerardo got involved in social media when Roger could not continue with that task. Roles are also self-negotiated: each of the founding members chose what they wanted to do when ${ }_{i} H$ jekrrh! was founded.

The founding members assume multiple roles in addition to their original role as translators. In this respect, they move beyond the boundaries of professional translation tasks and engage in other activities related to the self-publishing process. This, again, is closely related to the materiality of the translation and the empowerment that comes from digital publishing. Furthermore, the assumption of new roles is associated with a process of self-learning inside the core team. This is especially evident in the case of Juan and the making of the e-books.

This kind of self-learning evokes a community of practice: the group is informal, self-selected and formed by volunteer experts who share a common interest in translation. The learning has also taken place after they participate in a shared activity: for instance, when Juan details the problems he had to face when making the e-book for Alicia en el pais de las maravillas, or when Gerardo and Roger talk about the copyright problems to upload El guardavia, their narratives recall the experience and knowledge they acquired when facing specific difficulties in this shared project. Other aspects of $¡ H j$ jekrrh! also suggest that it is indeed a community of practice and, in fact, the three 'crucial' characteristics of communities of practice described by Wenger-Trayner and Wenger-Trayner (2015) are all applicable to ¡Hjckrrh!, namely: the domain, the community and the practice. Wenger-Trayner/Wenger-Trayner (2015) talk about a "shared domain of interest" in communities of practice and a commitment by members to the domain. In other words, as they are organised around a particular area of knowledge and expertise, members have "a sense of joint enterprise and identity” (Smith 2003). The domain is obvious in ¡Hjckrrh!, where most participants share a background in translation. As for the community, according to Lave and Wenger (1991: 98), members of a community of practice are involved in a set of relationships over time. $¡ H j c k r r h$ ! has now been publishing since 2013. During this time, members have helped each other, shared information, and engaged in joint activities and discussions, which is also typical of communities of practice (Wenger-Trayner/Wenger-Trayner 2015). In addition, members are practitioners (Wenger-Trayner/Wenger-Trayner 2015). ¡Hjckrrh! has also generated a shared repertoire of ideas, commitments and memories, and has developed resources such as tools (the webpage, the blog), documents (the e-books themselves), routines, vocabulary and symbols (Smith 2003). The workflow presented in the previous section is a good example of one of the routines established by the members of $i H j c k r r h$ !

Even though Gerardo acts as chief editor in most cases, as shown in the results section, there is a certain fluidity on the roles collaborators undertake. Depending on their time and motivation, some of them may assume more pro-active roles and do 'more' than just translate or review. In 
other words, some may use the possibilities of this increased agency that ¡Hjckrrh! allows. For example, after her initial collaboration as translator studied in this paper, the PI has recently acted as chief editor and commissioned two translations to two new collaborators (thus expanding Gerardo's second order network zone), still unpublished as of the date of drafting this paper. ${ }^{8}$ On the contrary, collaborators may subsequently lose their motivation or not devote as much of their free

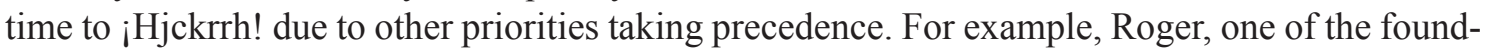
ing members, used to have a greater involvement during the earlier stages of ¡Hjckrrh!, but as he became busier and did not have as much free time to dedicate to this publishing initiative some of his original tasks were later undertaken by Gerardo.

\section{Conclusions: The empowerment of e-books}

The existence of $¡ H j$ jkrrh! is closely related to the possibilities provided by the e-book. In the interviews, the three founding members of $i H j c k r r h$ ! directly or indirectly refer to the empowerment and increased agency brought by new digital publishing possibilities. Talking about the origins of $i H j c k r r h !$, Roger explicitly says that he felt "there was something new emerging, something was happening, because it was the first time that people had the technology at their service to do things on the margins of publishing houses". In other words, the ebook has become a form of empowerment that has allowed the three founding members to create a different kind of production team. When comparing this production team to traditional publishing houses, certain differences become evident.

Translators can choose what they want to translate and publish, and can even re-edit translations they have previously published and give them new life. Translators can thus exert agency to act as initiators and cultural mediators at virtual zero risk - as there is no economic investment in ¡Hjckrrh!, and their only cost is time - however, revenue is also minimal.

In his role as 'chief editor' or leader of the production team, Gerardo contributes to the larger visibility of the translator by encouraging translators to write prologues and epilogues about the translation process. The translator is also included in the e-book cover, credits and retailers' platforms.

The interviews do not suggest that translators gain any form of symbolic capital. The involvement in this initiative does not seem to have any direct impact on the socio-professional status of its members. However, recent events suggest that this is changing. The current involvement of four early-career translators in the project suggests that they benefit from this experience. These four translators have not been interviewed since they have joined the initiative only very recently and after the data collection was over.

Sela-Sheffy (2016: 135) talks about "the contradiction between the potential power of translators and interpreters as cultural mediators (...), on the one hand, and their obscure professional definition and alleged sense of submissiveness, on the other". The underlying mechanics of ¡Hjckrrh! challenge the second part of this claim: translators have a clear understanding of their status as translators and exploit the possibilities of digital publishing to gain freedom and agency both as translators and cultural mediators. While the translators that participate in ${ }_{i} H \mathrm{H}$ ckrrh! may still be regarded as submissive because they accept to work for free, their attitude during the interviews - most of them were excited about having participated in this project and proud of it - does not really reflect any sense of submissiveness. Furthermore, they were all completely free to decide whether to engage in it or not. Gerardo describes ¡Hjckrrh! as "an experiment", and translators are invited to 'experiment' with it. Further research will analyse the reasons and motivations for participating in such a nonlucrative project. In brief, these motivations have to do with values such as experimentation, creativity, freedom, flexibility, leisure, vocation, excitement, friendship and trust.

8 The PI's recent involvement as a chief co-editor has taken place after the data collection and analysis of this study, and it will be further explored in future articles. 
In conclusion, this article attempts to contribute to the increasing body of sociological studies of translation by providing a detailed description of the roles and relations in a digital publishing initiative. ¡Hjckrrh! shares characteristics with communities of practice and this article has explored the potential of this approach to the study of production teams.

\section{References}

Austermühl, Frank 2001: Translation Practices Explained: Electronic Tools for Translators. Manchester: St. Jerome Publishing.

Buzelin, Hélène 2004: La traductologie, l'ethnographie et la production des connaissances. In Meta 49 (4), 729-746.

Buzelin, Hélène 2005: Unexpected Allies: How Latour's Network Theory Could Complement Bourdieusian Analyses in Translation Studies. In The Translator 11 (2), 193-218.

Buzelin, Hélène 2007a: Translations ‘in the Making’. In Wolf, Michaela/Fukari, Alexandra (eds.), Constructing a Sociology of Translation. Amsterdam/Philadelphia: John Benjamins, 135-169.

Buzelin, Hélène 2007b: Translation Studies, Ethnography and the Production of Knowledge. In St-Pierre, Paul/Kar, Prafulla C. (eds.), Translation - Reflections, Refractions, Transformation. Amsterdam/Philadelphia: John Benjamins, 39-56.

Chesterman, Andrew 2009: The Name and Nature of Translator Studies. In Hermes - Journal of Language and Communication Studies 42, 13-22.

Coldiron, Anne, E.B. 2012: Visibility Now: Historicizing Foreign Presences in Translation. In Translation Studies 5 (2), 189-200.

Cronin, Michael 2003: Translation and Globalization. London: Routledge.

Dam, Helle V./Zethsen, Karen Korning 2009: Translation Studies: Focus on the Translator. In Hermes - Journal of Language and Communication Studies 42, 7-12.

D’Hayer, Danielle 2012: Public Service Interpreting and Translation: Moving Towards a (Virtual) Community of Practice. In Meta 57 (1), 235-247.

Dickinson, Jules Carole 2010: Interpreting in a Community of Practice a Sociolinguistic Study of the Signed Language Interpreter's Role in Workplace Discourse. PhD thesis, Heriot-Watt University [online]. http://hdl.handle. net/10399/2387 (accessed 09 May 2017).

Emmerich, Karen R. 2013: Visibility (and invisibility). In Gambier, Yves/van Doorslaer, Luc (eds.), Handbook of Translation Studies: Volume 4. Amsterdam/Philadelphia: John Benjamins, 200-206.

Fox, Stephen 2000: Communities of Practice, Foucault and Actor-Network Theory. In Journal of Management Studies 37 (6), 853-867.

Gambier, Yves/van Doorslaer, Luc (eds.) 2010-2017: Subject index. Handbook of Translation Studies Online [online]. https://benjamins.com/online/hts2/list/jats-subjects (accessed 10 May 2017).

Gieryn, Thomas F. 1983: Boundary-Work and the Demarcation of Science from Non-Science: Strains and Interests in Professional Ideologies of Scientists. In American Sociological Review 48 (6), 781-795.

Grbić, Nadja 2010: "Boundary work" as a concept for studying professionalization processes in the interpreting field. In Translation and Interpreting Studies 5(1), 109-123.

Hale, Sandra 2007: Community Interpreting. Basingstoke/New York: Palgrave McMillan.

Hale, Sandra 2008: Controversies over the Role of the Court Interpreter. In Valero-Garcés, Carmen/Martin, Anne (eds.), Crossing Borders in Community Interpreting: Definitions and Dilemmas. Amsterdam/Philadelphia: John Benjamins, 99-121.

Hayles, N. Katherine 2008: Electronic Literature: New Horizons for the Literary. Notre Dame, Indiana: University of Notre Dame Press.

Hewson, Lance/Martin, Jacky 1991: Redefining Translation: The Variational Approach. London/New York: Routledge.

Ingold, Tim 2008: Anthropology is Not Ethnography. In Proceedings of the British Academy 154. Oxford: Oxford University Press, 69-92.

Jones, Francis R. 2009: Literary Translation. In Baker, Mona/Saldanha, Gabriela (eds.), Routledge Encyclopedia of Translation Studies, $2^{\text {nd }}$ edition. London/New York: Routledge, 152-157.

Katan, David 1999: Translating Cultures: An Introduction for Translators, Interpreters and Mediators. Manchester: St. Jerome Publishing.

Katan, David 2016: Translation at the Cross-roads: Time for the Transcreational Turn? In Perspectives, 24 (3), 365-381. 
Koskinen, Kaisa 2000: Beyond Ambivalence - Postmodernity and the Ethics of Translation. Academic dissertation. University of Tampere. Tampere: Acta electronica universitatis tamprerensis.

Koskinen, Kaisa 2006: Going into the Field: Ethnographic Methods in Translation Studies. In Wolf, Michaela (ed.), Übersetzen - Translating - Traduire: Towards a "Social Turn”? Münster/ Hamburg: Lit Verlag, 109-118.

Koskinen, Kaisa 2010: Agency and Causality: Towards Explaining by Mechanisms in Translation Studies. In Kinnunen, Tuija/Koskinen, Kaisa (eds.), Translators’ Agency. Tampere: Tampere University Press.

Koskinen, Kaisa/Dam, Helle V. 2016: Academic Boundary Work and the Translation Profession: Insiders, Outsiders and (Assumed) Boundaries. In The Journal of Specialised Translation 25, 254-267.

Latour, Bruno 1991: Nous n'avons jamais été modernes. Paris: La Découverte.

Lave, Jean/Wenger, Etienne 1991: Situated Learning: Legitimate Peripheral Participation, Cambridge: Cambridge University Press.

Lin, Chi-Lien 2012: Estudio estilístico contrastivo de las seis traducciones al chino de Platero y yo. PhD thesis, Universitat Autònoma de Barcelona [online]. http://hdl.handle.net/10803/96414 (accessed 10 May 2017).

Littau, Karin 1997: Translation in the Age of Postmodern Production: From Text to Intertext to Hypertext. In Forum for Modern Language Studies 33 (1), 81-96.

Littau, Karin 2011: First Steps Towards a Media History of Translation. In Translation Studies 4 (3), 261-281.

McKnight, Cliff/Dillon, Andrew/Richardson, John 1992: Hypermedia. In Kent, Allen (ed.) Encyclopedia of Library and Information Science, Vol. 50, New York: Marcel Dekker, 226-255.

Mayring, Philipp 2000: Qualitative Content Analysis. In Forum: Qualitative Social Research 1 (2) [online]. http://www. qualitative-research.net/index.php/fqs/article/view/1089/2386 (accessed 10 May 2017).

Nord, Christiane 1991: Text Analysis in Translation: Theory, Methodology and Didactic Application of a Model for Translation-Oriented Text Analysis. Amsterdam/New York: Rodopi.

O’Hagan, Minako/Ashworth, David 2002: Translation-Mediated Communication in a Digital World: Facing the Challenges of Globalization and Localization. Clevedon: Multilingual Matters.

Peña, Salvador 1997: El traductor en su jaula: hacia una pauta de análisis de traducciones. In Morillas, Esther/Arias, Juan Pablo (eds.), El papel del traductor. Salamanca: Colegio de España, 19-57.

Pressman, Jessica 2008: Navigating Electronic Literature. In Hayles, N. Katherine, Electronic Literature: New Horizons for the Literary [online]. http://newhorizons.eliterature.org/essay.php@id=14.html (accessed 10 May 2017).

Risku, Hanna/Dickinson, Angela 2009: Translators as Networkers: The Role of Virtual Communities. In Hermes Journal of Language and Communication Studies 42, 49-70.

Sela-Sheffy, Rakefet/Shlesinger, Miriam (eds.) 2011: Identity and Status in the Translational Professions. Amsterdam/ Philadelphia: John Benjamins.

Sela-Sheffy, Rakefet 2016: Profession, Identity and Status. In Angelelli, Claudia V./ Baer, Brian James (eds.), Researching Translation and Interpreting. Milton Park/New York: Routledge, 131-145.

Smith, Mark K. 2003: Communities of Practice. The Encyclopedia of Informal Education [online]. www.infed.org/ biblio/communities_of_practice.htm (accessed 10 May 2017).

Somers, Harold (ed.) 2003: Computers and Translation: A Translator's Guide. Amsterdam/Philadelphia: John Benjamins.

Venuti, Lawrence 1995: The Translator's Invisibility: A History of Translation. London: Routledge.

Wadensjö, Cecilia 1998: Interpreting as Interaction. London: Longman.

Wenger, Etienne 1999: Communities of Practice: Learning, Meaning and Identity. Cambridge: Cambridge University Press.

Wenger-Trayner, Etienne/Wenger-Trayner, Beverly 2015: Communities of practice: a brief introduction [online]. http:// wenger-trayner.com/introduction-to-communities-of-practice/ (accessed 25 November 2017).

Wolf, Michaela 2002: Culture as Translation - and Beyond: Ethnographic Models of Representation in Translation Studies. In Hermans, Theo (ed.), Crosscultural Transgressions: Research Models in Translation Studies II: Historical and Ideological Issues. Manchester: St. Jerome Publishing, 180-192. 